\title{
开展深部地貭研究的重大意义 及其发展方向
}

\author{
張文佑孙广忠
}

近时期来，地稹学界出現了一个振奋人 心的口号一向地球深部进軍! 它紧紧地吸 引着地盾科学工作者的注意力。許多人在思 考着、在議論着这个問題。它已經被視为是 地盾科学发展中一个重大的事件。

\section{- 深部地盾研究是地盾科学 发展的一个重要方向}

地稹学成为一門独立的学科已有二百余 年的历史了。在这漫长的岁月里, 为了滿足 生产实践的需要，地稹工作者曾經做过許多 地稹考察和实驗工作，取得了許多成績，在 一定范围內掌握了一些地稹规律, 建立了一 些地稹理論, 解决了一些实践中提出来的問 題，使地稹学发展成为一門具有多分支的、 龙大体系的学科。

在此同时, 我們也清楚地看到, 地稹学 中还存在着許多問題。它的水平还远远不能 满足生产实践的需要; 許多重大的、基本的 問題和理論还存在着爭論。造成这种状况的 原因是很多的, 而最主要的是, 对地球深部 的地稹状况还不够了解。

地质学研究的基本任务之一是解决国民 經济建設中所需要的矿产資源的来源問題。
許多年来，地稹工作者通过考察、实驗 和綜合分析工作获得了許多找矿的經驗, 掌 握了一些矿床的形成規律。如已經查明, 許 多內生矿床的成矿元素常与一定类型的岩浆 岩存在着共生关系。它表明內生矿床的形成 和分布与岩浆岩的形成和分布存在着成因上 的密切联系。要解决內生矿床的成因和分布 規律, 必須解决岩浆岩形成、岩浆活动反岩 浆起源等一系列問題。

地貭学家在很久以前已經查明，岩浆岩 按其化学成分可分为酸性、中性、基性及超 基性。拜从組成岩浆岩的矿物共生組合关系、 岩体內存在的岩相变化的事实及实驗室所得 到的矿物形成的温度和压力条件的試驗 結 果, 确立了岩浆岩形成的“岩浆分异”假說。 并进一步对岩浆来源問题做了若干推論。

由于实驗岩石学的发展, 特別是近年来 摸拟地下不同深度的温压条件的高温高压地 稹試驗工作的迅速发展及变稹岩区域內花南 岩类岩石成因的研究, 愈来愈多的地稹学者 开始怀疑所有的岩浆岩都是由玄武岩浆經过 分异而形成的岩浆岩成因的假說，而出現了 “花南岩化”理論。这个理論訩为, 很大一部 分花崗岩类岩浆岩是由沉积岩在地槽发展过 
程中被带入地球深部，經过重熔、浴出、冷 却或在地球深部的高温高压环境下进行交代 換貭而形成的。这一概念，近三十年来經过 苏联及北欧的一些岩石学家的砰究，已經乍 来愈多地被一些地盾学家所接受，从而出現 了两种或多种岩浆源的岩浆岩成因及相应的 矿床成因的理論。

随着对各种地稹現象訩識的进一步深 入，地稹学家已經注意到岩浆岩的空間分布 及在时間上演化的規律問題。特別是近时期 来,对大地构造及地壳运动問題的深入政究, 岩浆活动与大地构造碑究的密切結合，使人 們愈来㥿清楚地䚯識到，岩浆岩的成分及其 形成常与一定的大地构造单元及其发展阶段 有着密切的关系。如地売发展处于地壳拗陷 阶段时，常出現基性岩浆活动; 在地壳隆起 阶段时，常件随有酸性岩浆活动。如在地槽 早期下沉阶段,常有基性和超基性岩浆活动; 到了地槽发展的中期、晚期迥返上升阶段， 在地槽中央部分件随着产生有大量的花崗岩 浆活动，形成各种类型的花南岩侵入体。而 在地台发展的末期，一般又有沿断裂出現的 基性岩浆嘪发。

在上述研究的基础上，并考虑了已获得 的与深部地稹有关的地球物理資料，1950年 H. 包切尔特及 E. 特呂格尔对岩浆起源、岩 浆活动及岩浆岩形成，以及內生矿床形成等 問題进行了綜合的研究，而訩为原始岩浆有 二，郎玄武岩浆及再熔化矽鋁层混合岩浆。 他們部为地下深 $10 \sim 20$ 公里处的孔拉德界 面以上部分的地壳系由千枚岩、各种片称岩 及閃长岩等組成, 其下至深度为 $30 \sim 40$ 公 里的莫霍洛維奇界面之間部分是由輝长岩及 橄欖輝长岩类的基性岩組成的。莫霍洛維奇 界面是上述基性的輝长岩和橄欖輝长岩类岩
石与超基性的橄㰖岩和二輝橄欖岩类岩石的 分界面。橄欖岩层以下由于地球內部压力継 續增加，岩石密度加大，橄欖岩及二:輝橄欖 岩轉变为純橄欖岩。再下，就将成为高压下 的榴輝岩。这种岩石內富含碱金属及揮发組 分，其深度約为 60 公里。至于深 $80-100$ 公 里的谷屯堡低波速层則大概是再熔化带。在 这一深部地貭假設图式基础上，他們提出， 玄武岩浆系起源于深約 60 公里的榴輝岩层 或更深一些的谷屯堡低波速层內。再熔化矽 鋁层混合岩浆主要是在孔拉德界面处形成 的。H. 包切尔特及 E. 特克格尔靽以此种假 設图式为基础，制訂了岩浆活动及內生矿床 成因理論。在以后的䃑究工作中，又有人对 上述理論进行了补充和发展。这只是許多地 稹学家試图以深部地貭假設为基础，探討統 一的地稹作用的一个例子。

显然, 这种理諭的正确与否, 在极大程 度上决定于对深部地稹状况所做的假定是否 正确。这样就提出了，要解决岩浆岩形成、 岩浆活动及岩浆起源等問題，必須对地球深 部的地貭状况进行䂰究。

从上述可以看出，岩浆活动与地壳运动 和大地构造发展之間存在着密切的关系。甚 至可以說，岩浆活动是受大地构造发展和地 壳运动过程严格控制着的。因此, 大地构造 研究对解决岩浆活动及內生矿床分布規律具 有十分重要的意义。

此外，地壳运动及大地构造，特別是新 构造运动的研究，对解决重大工程建筑稳定 性亦有极重要的意义。我們知道，任何一項 重大的工程建筑开始之初都要求对建筑地区 地貭背景做出可靠的研究，对地壳活动程度 （如地壳差异变形及断裂活动性、地震活动 性) 做出評价, 以便在工程規划(如建筑場地 
选择)、設計和施工中采取措施保証工程建 筑的安全持久。故在大区域工程地貭区划工 作中常以大地构造特征做为基本依据之一。

人类在其实践活动中很久以前已經訩識 到，地球的表层一一地壳在地盾发展历史过 程中,曾經产生过剧烈的变动。这种变动过程 称为“地壳运动和演化”。地壳运动和演化的 結果, 一方面表現为組成地壳的岩体发生变 形,如岩体发生禇曲、断裂和引起地形变化; 另一方面則表現为組成地壳的物稹改組, 如 岩石变稹、岩浆侵入和噴出及新的堆积物形 成等。如此，常常使地壳运动前的大地构造 特征, 經过地壳运动发生了变化, 关在地壳 运动后形成的大地构造图案里留下了地壳运 动和演化的痕迹。在地面上我們經常可以看 到这些痕迹。它給我們提供了趼究地壳运动 及大地构造演变过程的綫索。

地稹学家多年来不解的劳动，查明了大 地构造发展过程中表現出来的許多事实, 其 中最重要的是地槽和地台以及构造运动期的 发現。这些事实奠定了大地构造学的基础。

近年来，世界上許多国家已經編制了不 同精度的区域大地构造图，并且已經出現了 世界大地构造图。这些資料为探索大地构造 发展及地壳运动理論問題提供了重要依据。 現在我們已經知道，整个地球的大地构造可 以划分为海洋及大陆两种大地构造单元。它 們之間存在着許多差別。大陆地壳又可按上 述概念划分出許許多多的地台及不同时代的 地槽。它們巧妙地結合在一起构成了大地构 造图案。今天显現于我們眼究之內的大地构 造图案, 是地壳运动及演化的历史发展結果。 地壳运动动力学及地壳演化的物理化学过程 究竟如何? 很长时期以来，地稹学家、地球 物理学家及地球化学家都曾尝試过解决这个
問題。但由于对深部地稹状况研究不足, 所 以这种尝試目前向未获得显著的成果。

实际上，地壳运动及演化結果在大地构 造特征上遺留下的痕迹不仅在地面上有所反 映，同时，亦必定在梁部构造上有所記載。 显然, 在解决大地构造发展及地壳运动問題 时，除了应对地面上所显示出来的地稹事实 进行仔細的研究外, 还必須对地球深部的地 貭特点做出研究。在这方面，地球物理工作 已經获得了若千值得注意的資料。

近年来用地震波进行梁部探測結果裴 明, 大洋地区地壳厚度多为 $10-15$ 公里, 个 別地区仅为 4-5 公里左右,而大陆地区地觉 一般厚度为 30-40 公里; 山岳地区尤較平原 及盆地地区为厚，一些山岳地区地壳厚度竟 达 60一70 公里。我們知道, 大陆上本原及盆 地地区多属地台构造，而山岳地区多属地槽 构造。对地震波資料进一步分析得知，大洋 地区地壳剖面的波导性相当均匀; 地震波通 过它的䋱波速多为 $6-7$ 公里/秒; 大陆地区 地壳剖面呈現为双层結构特征, 其上部䋱波 速为 5-6 公里/秒, 下部为 6-7 公里/秒。 根据地貭观测及高温高压試驗賣料对比制 断，一般訩为，大洋区地壳的物盾成分相当 于輝长岩类岩石; 大陆区地壳上部相当于化 南岩类岩石, 下部相当于輝长岩类岩石成分。 P. M. 唗米尼茨卡姃(1958)对不同地区 不同大地构造单元的地震波資料分析得出, 加里东及前寒武紀褶皱带地区地壳厚度一般 为 25-35 公里、海西褶皱带地区地売厚度一般为 38-42 公里左右, 而阿尔卑斯褶秡带地 区則变化于 50-70 公里之間。 И. П. 柯斯 明斯卡㛏(1958)进一步指出，古老地台区地 壳一般厚 30 公里, 上部为花南岩类岩层, 下部为輝长岩类岩层, 二者之間的界限㪶不 
明显; 活化地台区地壳厚达 50 余公里, 其中 花崗岩类岩层厚的 10 公里左右, 而輝长岩类 岩层厚达 40 余公里; 年青地台区地壳厚度一 般約为 35 公里,其中沉积岩层厚約 4 公里, 花南岩类岩层厚的 10 公里, 而輝长岩类岩 层厚度䄪占整个地壳厚度的 $2 / 3$ 以上; 山区 地壳厚度达 60 公里, 沉积及变稹岩层厚約 5 公里, 花南岩类岩层厚度达 30 公里, 輝长岩 类岩层厚度略薄于花崗岩类岩层, 約为 25 公 里; 拗陷带地壳厚度达 40 公里, 这类地壳中 花崗岩类岩层缺失, 輝长岩类岩层厚度約占 整个地壳厚度的 $1 / 2$ 强, 其余的为沉积岩 层。如果事实确是如此的話, 这些資料給我 們提供了如下一个初步的概念，郎地壳隆起 区花崗岩貭岩层較厚，而凹䧄地区地壳內輝 长岩稹岩层占优势; 現代地势較高的年青的 地台区地壳內花侖岩稹岩层一般比在現代地 势較低的古老的地台区地壳內的为厚。这可 能是由于在隆起区下面由于岩层向上凸起产 生空位，下降区地壳內花南岩层受到挤压发 生塔解; 熔融的花融岩一方面向隆起产生空 位地区运移，使隆起区地壳內花崗岩貭岩层 变厚; 另一方面，啙融的花崗岩层与其下面 的基性岩层起同化作用，如此，使凹陷区地 壳內花崗岩稹岩层变薄, 而輝长岩稹岩层就 显得比較厚了。这些䚿識显然是极初步的， 但它們已显示出，这方面研究对解决大地构 造性稹及其发展的重要意义。

上面所談的只是地壳特征的一个方面， 郎地壳結构的物理特征。这些物理特征的物 貭基础是什么呢? 它究竟是由什么組成的和 怎样形成的呢? 这个問題与大地构造的发展 和岩浆活动間題間存在着密切的关系。如上 所远，目前流行的概念是地壳的上部概由花 峒岩类岩层組成的，下部可能是由輝长岩类
岩层所組成。这种䚯識不是沒有爭論的。前 面我們轓經談过, $\mathrm{H}$. 包切尔特筸訩为孔拉德 界面以上是由閃长岩及变稹岩所組成; 而孔 拉德界面至莫霍洛維奇界面之間部分系由輝 长岩类岩石組成。J. T. 維尔逊(1957)誩为莫. 霍洛維奇界面为原始地面，上复岩浆岩系沿 深断裂涌出超复于原始地面之上的結果。最 近 U. A. 列贊諾失(1962)在分析地台区地壳 地震測深法所取得的地震波速度的資料时， 注意到用反射波法所获得的通过地壳內某一 地层內的层波速度較用折射波法所得到的相 应地层的界面的波速为小这一現象，而訓为 以前用界面波速資料来确定地壳成分的做㳂 是不正确的。他根据层波速度資料与 F. 具 尔奇 (1960)所提出的岩石中压縮波速度高压 試驗結果对比而提出了整个地壳全为变质岩: 所組成的看法。他訩为，地壳內部存在的地 震波界面(包括莫霍洛維奇界面在內)是不同 地貭时代的构造面。新老地台的差別是由組 成它們的物貭密度和基性不同而引起的。

B. A. 馬格尼茨基 (1961) 指出：“实际: 上，未必有人能怀疑地壳是在地壳发展的历 史过程中由其內部分离出来的，而首先是由 地肉的上部分离出来的。然而如何产生这一 作用，則至今倘未查明”。显然，要查明这 一問題，必須进行染部地稹的䃟究。

上面几个另星事实說明，媣部地稹問題 在地盾学进一步发展的过程中，已經成为急 需解决的問題。因此, 近年来, 深部地稹研 究愈来愈多地吸引着各方面学者的注意。它 已經成为地貭学发展的一个重要方向。

\section{二 急待解决的深部地稹課題}

媣部地稹和許多其他地稹問題一样，人 类对它的探索曾經經历过很长一段历史过 
程。正是由于有了这样的一个历史探索过 程，才使我們今天得以明确急待解决的深部 地稹問題之所在和解决这个問題的途径。

大致說来，在二十世紀以前，人类对地 球深部的探索主要是建立在地面地貭覌測及 天文学㸴究所确立的假說基础上，結合建立 与地壳运动和岩浆活动有关的地稹理論和假 說而进行深部地稹状况的探索活动。

二十世紀以来，地貭科学的一个重要分 支一一地球物理学（具体些說是固体地球物 理学)获得了蓬勃的发展。它給深部地稹研究 带来了巨大的活力，为深部地貭研究建立了 較完备的地球物理深部探測技术基础。半已 取得了大量的与訩識深部地貭状况密切有关 的地球深部結构及其物理性貭方面的資料。

大家熟知的, 1909 年 A. 莫霍洛維奇发 現的地下数十公里深度地方存在着的莫霍洛 維奇界面及 1914 年地球物 理学家 B. 谷屯 堡发現的地球深部 2,900 公里地方存在着的 谷屯堡界面，便是这些重要成就的一部分。

这两个重要的发現奠定了通用的地球深 部結构分层的基础。据此，通常把莫霍洛維 奇界面以上的地球表层部分称为“地壳”，把 谷屯堡界面以下部分称为“地核”。地壳与地 核之間厚达 2,800 余公里部分称为“地肉”(英 文名为 “Mantle”，俄文名为 “Мантия")。

进一步研究証明，地壳、地肉及地核內 部也乎非是均一的。1925 年 V. 孔拉德发現 在沉积盖层底莫霍洛維奇界面間存在着一个 界面，它被称为孔拉德界面。1947 年 B. 谷 屯堡发現在深度約为 80-140 公里一带还存 在着一个地震波通过它时，产生波速降低現 象的层,这层被命名为谷屯堡低波速层。近年 来研究证明，这一层在許多地区內确是存在 萧的。在大陆地区,其深部約为 120 公里,在
海洋区約为60公里左右。B. 谷屯堡(1959)进 一步指出，大陆区低波速层直接在莫霍洛維 奇界面下面；䋱波速度最小值(7.8 公里/秒) 发現于 80 公里梁度处，横波速度最小值 (4.4 公里/秒)发現于 150 公里深度处; 相应于莫 霍洛維奇界面处的䋱波速度 (8.1 公里/秒)出 現于 190 公里深度处，橫波速 (4.6 公里/秒) 在 270 公里深度处再次出現。此外，也发現 在 $413 、 900$ 公里及地核內 5,120 公里等深度 处也存在着类似的物理性稹异常的界面。

值得注意的是，近年获得的一些地稹現 象活动的梁度与前面所談到的莫霍洛維奇界 面、谷屯堡低波速层位置樑度，或籠統地說， 与地肉上部所进行的地稹作用密切有关。

例如，在夏威夷島曾覌測到两次与地震 活动有关的岩浆活动。根据所覌测到的地震 波的分析发現，第一次岩浆活动(1942年)的 岩浆源深度介于 $42-47$ 公里范围内, 溢出的 岩浆为含有少量的橄欖石的玄武岩; 第二次 发生在 1959 年，岩浆源㳭度約为 70 公里。 在勘察加及千島堡島覌測到的火山活动的岩 浆源深度約为 60 -70 公里。同样的資料在 巴尔干牛島南的地中海內的埃特納火山的研 觉中也得到过。該处火山活动的岩浆源深度 同样在 70 公里左右。

地震是近代地壳运动的一个特征現象。 对中亚地区地震震源研究的結果指出，該区 域地震震源比較集中于 $35 \pm 10$ 公里及 $100 \pm$ 20 公里两个深度处, 而在 60-80 公里深度 一带几乎沒有地震震源出現，250 公里以下 亦极少出現。对环太平洋地震带震源分析結 果得知，太平洋东岸南美地区最深震源哚达 660 公里，断裂面以 45-50 度傾角插入南 美大陆內，震源比較集中在 70-250 公里及 550-650 公里两个深度带，而在 250-550 
公里之間几乎没有覌測到有震源存在。太平 洋西海岸亚洲地区最深震源深达 650 公里, 断裂面䄪以 30 度的傾角插入亚洲大陆內。 震源分布机率同样存在着两个集中带, 郎 70-200公里及 350 公里以下部分出現較多; 而 200-350 公里深度一带出現較少。

还可以举出一些类似的事实。但仅就这 些, 我們已可看出, 要想对地壳运动、大地 构造发展及岩浆活动等問題得到进一步深入 的誡儎，必須对地肉上部，特別是谷屯堡低 波速层以上部分的深部地稹状况进行研究。

上述情况表明，1960年召开的国际大地 測量及地球物理会議上通过的“地肉上部研 究方案”中所提出的“为了解决岩浆活动、地 壳运动及大地构造发展等重大地貭問題，必 須对地球深部 1,000 公里以上部分进行研 究”，一般說来，是正确的。

我們知道，任何一个科学研究課題的选 定，不仅要根据生产实践及科学发展本身的 需要, 而且必須考虑到解决所提出的科学課 題的技术可能性。

显然，上面所提出的深部地貭課題可能 解决的程度，极大程度上則受地球物理深部 探測技术、高温高压下进行地貭模拟实驗技 术及超深鉆进技术等发展水平的控制。在下 面，我們还将会看到，根据天然地震波和大 地电磁波观測資料的分析，可以探測地球深 部梁达 1,000 公里以下部分的地球內部結构 和物理性貭; 人工地震測深工作可以較詳細 地探測清楚莫霍洛維奇界面以上部分的地球 結构和物理性貭; 高温高压試驗工作对解决 莫霍洛維奇界面以上部分的深部地貭状况及 作用可以提供相应的資料; 如果能够合理地 选择鉆孔的位置，則超深站进工作将会对解 决莫霍洛維奇界面以上部分的地貭結构提供
出最有价值的資料。由此, 我們可以得到这 样一个結論, 即当前深部地貭研究的中心課 題确定为谷屯堡低波速层、莫霍洛維奇界面 的本稹及地壳的結构和发展过程問題是正确 的。如果考虑到地壳問題研究的意义及現状 的話，我們訩为，当前更急待解决的深部地 貭課題則为地壳及其发展問題。这个問題的 研究对地貭科学进一步的发展具有最現实的 意义。我們訩为, 1961 年在巴黎召开的国际 地球物理委員会会議上所提出的目前妍展深 部地貭研究的最主要的八个課題可以做为我 們目前开展深部地稹㸴究的行动課題。这八 个課題是: 1. 地肉上部的結构、大陆利海洋, 以及各个不同构造带下面的地壳結构特点;

2. 地震震源机制問題；3. 莫霍洛維奇界而的 本貭; 4. 电导率随深度变化的原因; 5. 地肉 上部的低波速层的成因; 6. 过渡层的性稹;

7. 地肉中接近熔点的温度带的存在問題;

8. 在地稹时期中构造作用及岩浆活动的演化 問題。

該会議并建議，上列八个問題的研究应 該在地盾、地台、褶䏢带、活化带、島屿、 深洋盆地、內海及洋底山脉等不同大地构造 单元及地理区域內进行。这些問題，目前在 許多国家內正在积极地筹备和开展着。

\section{三 深部地稹研究的途径}

前面我們已經談过，深部地貭是地貭学 的一部分。深部地稹研究工作不仅要解决現 阶段地球深部結构、物貭組成特点及其物理 状态，而更重要的是要解决它在地球形成以 后的不同阶段的地稹历史发展过程中的状 态、演化及其所产生的深部地貭作用。据此, 我們訩为, 深部地貭研究的基本途径应該是: 在地面地稹現象覌察、綜合的基础上，采用 
物理試驗(高温高压地貭試驗等)、地球物理 探測及超深鉆探的技术，与地球物理学家、 地球化学家亲密协作，由浅到深，由今及古， 层层深入, 今古对比的方法, 有計划、有步 驟地逐步开展。換句話說，郎深部地稹㸴究 在現阶段应該在地面地貭考察和綜合分析中 获得的岩浆活动、地壳运动及大地构造发展 現代过程訩識的基础上，結合深部地球物理 探測、高温高压地稹試驗及超深鉆探工作获 得的直接或間接的資料，探討与岩浆活动、 地壳运动及大地构造发展可能密切有关的部 位的深部地貭現代特征及其所产生的地貭作 用; 另一方面，应該在現代樑部地貭特征及 其作用研究結果的基础上，結合地面地貭考 察、綜合所获得的岩浆活动、地壳运动及大 地构造发展的历史規律資料，探討深部地稹 的历史发展过程。并在此基础上，再进一步 地向更深部探索。

如此，我們訩为，要解决上面所提出的 深部地貭問題，必須进行以下゙一些工作:

1. 以編制大地构造图为綱，开展綜合地 貭普查，綜合分析地面地稹考察所获得的資 料，注意新构造及近代地壳运动，特別是地 震的䂰究。

地貭普查工作中，应注意运用磁法、重 力及地震勘探等地球物理勘探技术，以便获 得不同类型的大地构造单元的地球物理特征 及一定梁度处的深部結构資料。并結合新构 造、近代地壳运动, 特別是地震机制的研究 結果，以获得近代地壳运动及新构造运动发 展过程及其力学机制的深部地貭基础及其控 制作用。在地貭普查及資料分析过程中还应 該注意与大地构造单元发展过程密切有关的 岩石建造規律的研究，以期䦎明大地构造发 展过程中的物稹演化問題，从而为探索深部
物貭演化提供綫索。

上述䂧究成果可以通过編制大地构造图 的方式来概括。根据前面所開述的深部地貭 研究途径，在編制大地构造图时，則不仅要 編制一般的大地构造图，而且还要編制出不 同地稹时期的大地构造图及不同深度的大地 构造图，以便由浅到深地、由今及古地探討 深部地貭特征及其发展过程。这种大地构造 图，实际上，目前已有不少国家的地貭学者 尝試过。我国在这方面亦作了若干尝試。

2. 从岩石建造观点出发，系統地开展岩 浆活动及变稹作用以及岩石和矿物在不闰温 度和压力下相态变化的研究。加強岩石化学 及地球化学的研究。

这些研究中应当注意进行近代火山及前 寒武紀古老的岩石和可能为地球深部組成物 稹的岩石，如橄欖岩、純橄欖岩等的砟苝。

如果我們承訩，組成地球表层的岩浆岩 是深部物貭演化分异的产物的話，則岩浆岩 的研究就不应該停留在仅对地面表露出来的 岩石进行观察、分析；而还应該在高温葻压 下进行岩石和矿物的合成、相态轉变的温压 条件的研究。

岩石学研究，包括岩浆岩、变貭岩、沉 积岩，还应該注意进行岩石中所含的放射性 物稹的类型、衰变过程及其含量的研究。这 方面研究对解决深部地貭演化过程中的放射 性物稹作用，如地热发生、矿物形成以及岩 石絕对年龄測定等問題都是一分需要的。

变貭作用的破究，特別是变稹矿物形成 和轉化的温度和压力条件的研究是解决深部 物貭演化过程的一个重要綫索。这力面䂧究 应当与高温高压地稹試驗及古地热㸴究紧密 配合着进行。

应当訩識到，岩浆起源与变貭过程之間 
不存着明显的界限。梁成变稹岩与某些 岩浆岩的形成过程并无重大区別。这种覌念 在探索深部物稹演化中必須明确。

岩石学研究不仅要从矿物学观点出发研 究岩石的矿物成分、相态轉化，而且还要从 岩石化学及地球化学覌点出发, 研究組成岩 石的元素演化。

3. 开展深部地球物理探測工作。这是目 前获得地球深部結构及.其物稹組成特点的基 本手段之一。上面我們已經談过，在这方面 工作中对我們最有意义的技术是地震測深及 大地电磁測梁工作。但是这并不排斥一般綜 合性的地球物理勘探技术在解决深部地稹問 題方面的作用。在現阶段, 在探測地球浅层 构造及其物稹特点方面，地球物理勘探工作 还是很需要的。如磁法勘探可以使我們以較 便宜的代价获得結晶基岩面起伏情况的素 料; 重力測量結果不仅可以大致地确定浅层 构造情况，还可以借此資料估算地壳厚度和 研究大陆均衡問題等。不过这些方法对解决 剖面結构分层及更梁部結构，如确定谷屯堡 诋波速层的位置等問題方面却显得有些不 足; 地震測樑及电磁測媣, 特別是地震測深 技术，便显出它們的优越性。

利用地震波, 包括天然地震波分析及人 工地震測深, 研究地球深部物稹的物理性稹 及确定結构层位圆等工作目前在国外已經广 泛开展。在这些工作基础上，不仅使我們获 得了地球深部經向結构的輪廓，而且对谷屯 保低波速层以上部分結构层空間分布状况亦 有了概略性的了解。特別是在人工地震測梁 工作基础上，目前已可使我們对大西洋、太 平洋北部、北美、苏联、匈牙利等地区的莫 霍洛維奇界面、孔拉德界面等分布情况有所 了解，对不同地区的大地构造单元的地壳
結构特点获得了初步的訩識。这些工作說明， 深部地貭研究不仅是需要，而且这項技术的 目前水巫已提供了解决这項任务的可能性。

大地电磁測深工作已有初步的开端。苏 联、美国、匈牙利、英国及日本等国的学者 在这方面已經进行了一些工作。这項工作在 解决地球深部物稹組成方面有重要的意义。

我們知道, 在地震波研究基础上, 获得 的深部物貭传播弹性波速度的性貭仅是深部 物稹本稹所决定的物理性稹的一个方面，郎 机械性稹和相态方面。而在电磁測深基础上 荻得的樑部物稹电导率性稹, 則是与樑部物 稹本稹有关的物理性稹的另一个方面，郎其 金属性和化学性貭特点。传播波速度在极大 程度上决定于物稹的物理状态，而电导率主 要受其化学成分特点所控制。只有把这两方 面資料結合起来运用时，才能对䚿識深部物 稹本稹及其相态有較全面的了解。据此，我 們訩为，电磁測樑工作尽管还存在着許多問 題，但却很值得加以重悓和大力发展。

\section{4. 开展高温高压下岩石行为的試驗研究} 工作。这方面工作目前已經出現了有如下三 个方向:（1）在高温高压下对岩石和矿物的 物理性稹进行測定，为用深部地球物理探測 資料解释深部物稹組成提供基本素材。在这 一領域內，F. 貝尔奇、D.S. 休斯及 M. П. 渥 拉洛維奇等已經取得了許多有价值的成果。 D.S. 休斯等已經完成了 8,000 大气压， $400^{\circ} \mathrm{C}$ 温度条件下的一些岩石的传播波速度的性稹 及与此有关的物理性貭試驗工作。F. 貝尔奇 在1960 年发表了題为 “10,000大气压下岩石 中的压縮波速度”一文,該文对他自己多年来 所取得的試驗成果做了系統的总結。这些資 料被視为是最近用地震波資料判断深部物貭 本貭的基本依据。最近 M. П. 渥拉洛維奇在 
5,000 大气压下进行了岩石电导率的测 量工 作。上述情况表明，在这一領域內的工作对 解决莫霍洛維奇界面以上的深部地盾問題提 供有关資料完全有現实可能。对探索谷屯堡 低波速层来說 (压力約为 3-4万大气压, 温度 約为 $1,500^{\circ} \mathrm{C}$ ) 还需要做很大的努力; (2)在 高温高压下研究岩石及矿物的相态稳定条件 及其合成的温压条件，探討地球深部物貭本 稹及相态。岩石学家在这方面已經做出了大 量成果。如在某种特定的温度和压力条件下 已蟀得到了榴輝岩、橄欖石及尖晶石等人工 合成产物。1957年 E. C. 罗伯逊等在10,000 25,000 大气压和 $600-1,200^{\circ} \mathrm{C}$ 温度条件下 得到了鈵长石加霞石轉变为硬玉的实驗 結 果。最近，苏联科学院高压物理研究所及莫 斯科大学地球化学教研室在 16 万大气压和 $1,200 \sim 1,400^{\circ} \mathrm{C}$ 温度条件下得到了比重为 4.35 的石英新变种。很值得重視的是, 1960 年P. J. 維理和 O. F. 图特所发表的一个实驗 結果。花崗岩和頁岩在有水份加入时在 4,000 大气压和 $660^{\circ} \mathrm{C}$ 的温度条件下出現熔融現 象，而在同样压力下当水分中含有 $4 \%$ 的争 化氫时，其熔点温度可降低至 $590^{\circ} \mathrm{C}$; 同时 得到在 1,000 大气压下 $\mathrm{CaO}-\mathrm{CO}_{2}-\mathrm{H}_{2} \mathrm{O}$ 系的液 相界綫最低温度为 $675^{\circ} \mathrm{C}$, 而在 4,000 大气 压下为 $660^{\circ} \mathrm{C}$; 当加入 $\mathrm{MgO}$ 时, 在 1,000 大 气压和 $625^{\circ} \mathrm{C}$ 温度条件下郎可熔化。这些資 料对探索谷屯堡低波速层及莫霍洛維奇界面 的本稹，以及玄武岩浆源及花南岩化問題提 供了极有价值的綫索。（3）在高温全围压高 压条件下研究岩石力学性貭, 为探索地壳运 动的力学机制提供参考資料。目前这方面工 作开展的还不多。 D. T. 格萊格斯等人做了 一些工作。他在岩石力学性稹指标測定的同 时, 并进行了岩組学研究。上述一些情况表
明，高温高压下对岩石进行实驗研究不仅对 解决樑部地貭問題具有重要意义，而且对解 决谷屯堡低波速层以上部分的深部地貭問題 在技术上也是有可能的。

5. 开展超深鉆探工作。关于超深鉆探工 作的意义，如对于地下資源，特別是对热能的 利用开辟新道路等方面已有很多諭述, 在这 里我們不想多說。我們只想指出，超深站探 应当做为控制鉆来进行。今天的技术水平已 經提供了开展这項工作的可能。苏联、美国、 意大利、委內瑞拉和法国等許多国家已經实 現了 5,000米以上的深孔鉆进工作。据 H. C. 吉冒費也夫和 Я. A. 盖利夫加特的报导，美 国自 1938 年至 1960 年已打了 1,260 个 4,500 米以上的梁孔; 其中 1,000 个以上是在 1956 年到 1960 年期間完成的。1958 年在台克薩 斯州打了 7,723.6 米的深孔; 1960 年底在路 易西安納州开始了設計深度为 7,930 米的深 孔鉆进。1961年 3 月在墨西哥属的瓜达卢帕 島西开始了計划打穿莫霍洛維奇界面的超深 鉆进。苏联已提出了深度为 $12,000-15,000$ 米的五口超深鉆进計划，并宣布已掌握了鉆 入地下 20 公里深的鉆进技术。这一工作的 开展可以使我們确切地掌握一些地区的深部 地稹剖面的岩石相态和物稹成分，进一步了 解深部矿产及地热凟源分布情况，以及地面 地稹发展过程与深部地貭作用之間的关系。

目前开展超深鉆探工作确实是存在着很 大困难。但是从上面所介紹的一些資料中却 可以看出，如果合理地选择鉆孔位置，近代 的技术水平完全有可能实現前面所提出的現 阶段深部地稹研究課題中超深鉆探的任务。

超潹鉆探工作需要付出的經济开支是极 其庞大的。这就要求在确定超深鉆孔的位置 时必須特別壃重，并且必須有大地构造、岩石 
学、地球物理学及其他有关的科学技术专家 至加进行仔細的商討。超深鉆孔位置的确定 还必須以地球物理探測、群細的地面地稹及 地温研究为基础，而且要密切地結合当前急 需解决的地稹矿产資源勘探的任务来进行。

上面所談的仅是与梁部地貭研究最密切 有关的一些工作方面。除此以外，系統地进 行地球物理研究、开展隤石及宇宙地貭㸴究 对解决深部地稹問題来說亦是十分需要的。

綜合上述，我們可以看到，現代技术条 件完全有可能解决現阶段深部地稹研究的基 本課題，郎谷屯堡低波速层、莫霍洛維奇界 面及地壳的本稹及其发展过程等問題。显 然，深部地稹研究工作不仅是解决当前生产 实践及地貭科学进一步发展所迫切需要, 而 且，在技术措施上已經存在着开展这一工作 的可能, 并且这些工作結果反过来又可以促 进有关科学技术的发展。因此, 我們訩为, 今天把深部地貭研究提到科学研究的計划日 程上来是适时的，而且是必要的。

[1] B. B. 齐霍米洛夫, B. E. 哈茵：地盾学簡史, 地 质出版社，1959。

[ 2 ] B. B. 別洛鳥索夫: 大地构造学基本問題, 地盾出 版社, 1957。

[ 3] B. A. 馬格尼荻基: 大地物理学, 地盾出版社, 1956 。

[4] 渡边武男：岩石矿物の实驗研究から地壳探求人， 科学, 第 31 卷, № 4, 1961。

[5] 鈴木 平: 最近の高压物理学, 科学, 第 31 卷, № 6,1961 。

[6] 楖家荣: 成醇理論与找矿, 中国地盾, № 12, 1961。

[7] Г. Д Аффанасьев: Строение земной коры и некоторые проблемы петрографии, Изв. АН СССР, Сер. Геол. № 3, 1961.

[8] Дж. Т. Вилсон: Земная кора, "Планета эемля", Издат. И-Л. 1961.

[9] Г. С. Горшков: Некоторые вопросы теории вулканология, Изв. АН СССР, Сер. Геол. № 11, 1958.

[10] Р. М. Деменицкая: Основные черты строения коры земли по геоф. данным, Гостоптехиз- дат, 1961.

[11] И. П. Қосминская: Строение земной коры по сейсмическим данным, Бюл. МОИП. Отд. Геол., т. XXXII (4), 1958.

[12] В. А. Магницкий: Верхняя мавтия и её влияние на развитие земной коры, Вест. АН CCCP, № 11, 1961.

[1.3] И. А. Резанов: О строения земной коры платформенных областей, Бюл. МОИГТ. Отд. Геол., т. XXXVII (1), 1962.

[14] С. М. Стишов, С. В. Попова: Новая плотная модификация окиси кремия, Геохимия, № $10,1961$.

[15] Н. С. Тимофиев, Я. А. Гельфгат: Проблемы бурения глубоких скважин, Нефтяное Хо, зяйство, № 1, 1962.

[16] А. Н. Тихонов и др: Об электромагнитном зондировании глубоких слоев земии, ДАН, СССР, r. 140, № 3, 1961.

[17] Ю. М. Шейнман: Поверхность мохоровича, глубина зарождения магма и размешение ультрабазальтов, Сов. Геол., № 8, 1961.

[18] Д. И. Щербаков, Г. Д. Афанасьев: О некоторых задачах геологии в связи познания глубоких недр земли, Изв. АН СССР, Сер. Геол., № 10, 1961.

[19] F. Birch: The Velocity of Compressional Waves in Rocks to 10-kilobars, Part. I, I. Geophys. Res., vol. 65, № 4, 1960.

[20] D. T. Griggs, J. Handin, eds: Rock Deformation, M. Geol. Soc. Am., 1961.

[21] B. Gutenberg and C. F. Richter: Seismicity of the Earth, Priceton Univ. Press, Princeton, New Jersey, 1954.

[22] B. Gutenberg: The Lear of Low Velocity in Astenosphere, Ann. Geotis, № 4, 1959.

[23] B. Gutenberg: Physics of the Earth's Interior, Academic Prees, New York-London, 1959.

[24] D. S. Hughes, C. Maurette: Elastic Mave Velocity in Granites, Geophysics, vol. 20, 1956.

[25] D. S. Hughes, C. Maurette: Variation of Elastic Wave Velocity in Basic Ignous Rocks with Pressure and Temprerature, Geophys, vol. 22, 1957.

[26] K. L. McDonald: Penetration of the Geomagnetic Field Through a Matle with Variable Conductivity, J. Geophys. Res., vol. 62, № 1, 195\%.

[27] E. C. Robertson, F. Birch and G. J. F. MacDonald: Experimental Determination of Jadeits Stability Relation to 25,000 bars, Am. J. Sei., vol. 255, № 2, 1957 .

[28] P. J. Wyllie, O. F. Tuttle: Melting in the Farth's Crust, 21st. Int. Geol. Cong. Norden, P'art. 18, 1960. 